\title{
PERANCANGAN BUKU ILUSTRASI CERITA RAKYAT LEBONNA MASSUDILALONG
}

\author{
Fetia Safitri ${ }^{1}$, Abd. Azis Said ${ }^{2}$ \\ ${ }^{12}$ Desain Komunikasi Visual, Fakultas Seni dan Desain, Universitas Negeri Makassar \\ Corresponding Author: fetiasafitri65@gmail.com
}

\begin{abstract}
ABSTRAK
Perancangan ini bertujuan untuk membuat media informasi mengenai cerita rakyat atau legenda Lebonna Massudilalong di daerah Tana Toraja bagi remaja dalam bentuk buku ilustrasi. Metode perancangan yang digunakan adalah Research and Development atau penelitian dan pengembangan. Model pengembangan yang digunakan adalah model 4-D yaitu Define (pendefinisian), Design (perancangan), Develop (pengembangan) dan Disseminate (penyebaran). Namun, langkah-langkah penelitian yang dilakukan hanya (1) Define (pendefinisian), (2) Design (perancangan). Data penelitian didapatkan dari data pustaka, data dari narasumber ahli cerita dan ahli visual serta tanggapan siswa-siswi sekolah menengah atas terhadap materi komunikasi cerita rakyat Lebonna Massudilalong. Adapun konsep perancangan yakni antara lain, memilih versi cerita, menyiapkan sinopsis dan narasi cerita, membuat storyline dan storyboard, $m$ embuat konsep karakter, membuat sketsa ilustrasi cerita, digitalisasi, dan layout, serangkaian finalisasi akhir untuk memperkenalkan dan menarik perhatian serta minat remaja terhadap produk yang dibuat. Hasil perancangan ini berupa ilustrasi cerita rakyat Lebonna Massudilalong dengan buku fisik sebagai media utamanya. Sedangkan untuk media pendukung yang berfungsi sebagai media penyalur informasi dan publikasi yaitu berupa poster, $\mathrm{x}$-banner, totebag, mug, sticker, t-shirt, dan gantungan kunci.
\end{abstract}

Kata Kunci: Buku; Ilustrasi; Cetita Rakyat Toraja; Lebonna Massudilalong

\begin{abstract}
This design aims to make media information about folklore or legend Lebonna Massudilalong in the Tana Toraja area for teenagers in the form of illustrated books. The design method used is Research and Development. The development model used is a 4-D model, namely Define, Design, Develop and Disseminate. However, the research steps are carried out only (1) Define, (2) Design (design). The research data were obtained from library data, data from story experts and visual experts as well as high school students' responses to Lebonna Massudilalong folklore communication materials. The design concepts include choosing a version of the story, preparing a synopsis and narration of the story, making a storyline and storyboard, creating a character concept, sketching a story illustration, digitizing, and layout, a series of final finalization to introduce and attract the attention and interest of young people towards the product was made. The results of this design are in the form of illustrations of Lebonna Massudilalong folklore with physical books as the main media. As for the supporting media that function as a medium for channeling information and publications in the form of posters, x-banners, totebags, mugs, stickers, t-shirts, and key chains.
\end{abstract}

Keywords: Illustration Book, Toraja Folklore, Lebonna Massudilalong

\section{PENDAHULUAN}

Cerita rakyat adalah hasil imajinasi dan pola fikir dari orang terdahulu yang masih terikat kuat dengan tradisi dan isinya mengandung kearifan lokal, nilai-nilai, dan norma dimana cerita itu terlahir. Dan cerita rakyat ini diwariskan secara turun-temurun 
dari satu generasi ke generasi lainnya. Setiap cerita rakyat yang tersebar di gugusan nusantara mewakili identitas budaya dan kepribadian bangsa Indonesia. Segala kearifan dan kepribadian nusantara yang sangat kuat ini sudah diwariskan kepada generasi muda melalui metode pendidikan berbasis cerita rakyat. (Fitri Sundari, 2017: 103)

Indonesia adalah suatu negara yang terdiri dari berbagai suku bangsa, bahasa, dan budaya. Suku Toraja adalah salah satu suku bangsa yang ada di Indonesia, yang memiliki bahasa yang dipakai dalam berinteraksi dengan sesama. Selain itu, memiliki budaya yang dipelihara sejak dahulu kala secara turun temurun yang tercermin dalam keseharian suku Toraja. Dalam perjalanan kehidupan orang Toraja, mereka berkarya khususnya menciptakan karya seni sastra lisan yang bersifat anonim. Karya sastra lisan Toraja ini diwujudkan dalam berbagai bentuk, misalnya berupa cerita rakyat. Sama halnya mitos dan legenda tentang Toraja, karena dalam tradisi masyarakatnya tidak dikenal adanya tulisan dalam bentuk teks, dokumentasi, atau penuturan prosaik atau puitik, semua cerita hanya dikenal dalam bentuk lisan, sehingga akhirnya tidak semua anggota masyarakat Toraja mengetahui dengan pasti mengenai mitos dan legenda asal-usul nenek moyang mereka. Sejarah lisan ini hanya dikenal oleh orang-orang yang berpengaruh dalam masyarakat, seperti golongan bangsawan dan penguasa adat Toraja yang mempunyai Tongkonan (rumah adat), karena salah satu fungsi Tongkonan adalah sebagai tempat menyampaikan berita, cerita, legenda, dan filsafat hidup Toraja, dari generasi ke generasi (Said, 2004: 20-21).

Namun sekarang, zaman dimana cerita rakyat mulai kehilangan eksistensinya, terutama dikalangan remaja. Hal itu disebabkan karena adanya perkembangan teknologi dan arus globalisasi saat ini yang sangat pesat, maka tatanan kehidupan juga turut bergeser. Generasi muda tidak lagi mengenal cerita rakyat karena tidak ada lagi yang melanjutkan. Serta minimnya media yang menceritakan cerita rakyat membuat remaja tidak mengetahui dan kemudian lebih tertarik pada cerita dari luar negeri yang lebih menarik dan interaktif. Padahal, tidak semua cerita dari luar negeri memiliki nilai-nilai yang sesuai dengan yang kita anut selama ini atau tidak sesuai dengan kearifan lokal Indonesia. Cerita rakyat tidak lagi diceritakan oleh orang tua ataupun guru tetapi hanyalah sebagai sampingan yang tidak dianggap penting (Anne Veronica H, 2015: 25).

Mencermati kondisi tersebut, penulis mengangkat sebuah cerita rakyat Toraja untuk dikaji. Cerita rakyat yang akan diangkat adalah cerita rakyat yang berasal dari daerah Tana Toraja yaitu kisah cinta sejati antara Lebonna dan Massudilalong yang berakhir tragis. Banyak masyarakat Indonesia tidak terkecuali masyarakat Tana Toraja sendiri yang tidak mengetahui cerita tersebut. Sehingga dibutuhkan suatu usaha untuk memperkenalkan kembali budaya dan kebiasaan hidup di Tana Toraja dalam bentuk media informasi visualisasi cerita rakyat Lebonna Massudilalong yang dapat menarik perhatian remaja.

\section{METODE PENELITIAN}

$\begin{array}{lll}\text { Metode } & \text { yang digunakan dalam } \\ \text { penelitian ini adalah Research and } \\ \text { Development atau penelitian dan }\end{array}$
pengembangan. Model pengembangan yang akan digunakan adalah model 4-D (Four D) sebagai perangkat media informasi. Model ini dikembangkan oleh S. Thiagarajan, Dorothy S. Semmel, dan Melvyn I. Semmel (1974: 5). Model pengembangan 4D terdiri atas 4 tahap utama yaitu: Define (pendefinisian), Design (perancangan), Develop (pengembangan) dan Disseminate (penyebaran). Metode dan model ini dipilih karena bertujuan untuk menghasilkan produk berupa media informasi. Berdasarkan pendapat Sugiyono, dirumuskan tahap-tahap penelitian yang disesuaikan dengan kebutuhan. Penelitian yang akan dilakukan hanya sampai penelitian perancangan sederhana. Jadi, langkah-langkah penelitian yang akan dilakukan yaitu, (1) Define (pendefinisian), (2) Design (perancangan).

Pada tahap ini dilakukan studi kepustakaan terhadap berbagai referensi berdasarkan kata kunci perancangan yang akan dibuat. Data yang dikumpulkan diperoleh dari buku, jurnal, serta informasi lain dari berbagai sumber terpercaya. 
Pada teknik pengumpulan data ini, penulis membuat daftar pertanyaan (questioners) berbasis digital yang diedarkan di SMAS PGRI GENTENGAN kec. Mengkendek Tana Toraja yaitu dengan target remaja pada tanggal 16-17 November 2018. Teknik pengumpulan data wawancara yang dilakukan secara pribadi baik tertulis maupun menggunakan media rekam terhadap narasumber yaitu Bapak Belo Tarran selaku budayawan sekaligus Ketua Komite Nasional Pemuda Indonesia (KNPI) Toraja Utara pada tanggal 1 Mei 2019 dengan bahasan seputar cerita rakyat Lebonna Massudilalong, dan Toraja pada masa dahulu.

$$
\text { Penelitian ini menggunakan }
$$

pendekatan kualitatif dengan sedikit penyesuaian sesuai konteks penelitian yaitu metode yang memfokuskan pada pemahaman fenomena sosial dari sudut pandang partisipan secara deskriptif. Teknik analisis data kualitatif yang digunakan dalam metode penelitian atau perancangan buku cerita rakyat Lebonna Massudilalong, yaitu dengan mengolah dan menganalisis data-data yang terkumpul menjadi data yang sistematis, teratur dan bermakna.

Dalam studi kasus ini penulis membatasi ruang lingkup hanya pada cerita rakyat yang berasal dari daerah Tana Toraja yaitu kisah cinta sejati antara Lebonna dan Massudilalong yang berakhir tragis. Yang dikemas dalam bentuk media informasi dengan visual menarik dan target pembaca remaja yang berusia mulai $11-24$ tahun yang diharapkan telah mampu berpikir dengan baik dan dapat memaknai isi cerita.

\section{HASIL DAN PEMBAHASAN}

\section{Konsep Desain}

Konsep desain yang akan digunakan dalam media informasi ilustrasi cerita rakyat Lebonna Massudilalong adalah konsep tradisional budaya Toraja dengan menerapkan unsur-unsur budaya dari daerah Toraja. Unsurunsur yang dimaksud diantaranya dalam hal pemilihan warna, simbol- simbol, serta aset yang medukung cerita seperti pakaian, dan rumah adat. Selain itu, desain ilustrasi yang akan dibangun dengan nuansa cerita yang penuh emosi seperti romance, horror, dan akhir yang menyedihkan.

\section{Materi Pesan}

Versi cerita rakyat Lebonna Massudilalong yang akan digunakan adalah versi Sarira. Berikut sinopsis yang merupakan materi dari isi perancangan.

\section{Sinopsis}

Berawal dari adanya sosok wanita cantik bernama Lebonna yang sangat dikagumi oleh banyak pria di kampungnya, dan ada pula pria gagah perkasa yang merupakan pahlawan atau pemberani di kampung yaitu Massudilalong. Mereka pun saling jatuh cinta dan memutuskan untuk mengikrarkan janji sehidup semati. Namun, banyak orang merasa iri dan cemburu terhadap hubungan Lebonna dan Massudilalong. Sampai suatu ketika terjadi penyerangan dari kampung sebelah yang mengharuskan Massudilalong memimpin pasukan untuk berperang. Ditengah peperangan, seorang anak buah Massudilalong melarikan diri dan menuju rumah Lebonna untuk menyampaikan berita bohong bahwa Massudilalong tewas dalam peperangan yang menyebabkan Lebonna sakit hati dan memilih untuk menepati janji sehidup semati dengan cara bunuh diri. Sepulang Massudilalong dari perang, ia mendengar kabar kematian Lebonna yang membuatnya sangat bersedih hingga setahun kemudian ia memilih menikah dan memiliki seorang anak bernama Paerengan. Hari-hari berlalu hingga seorang pembantu Paerengan bernama Dodeng yang sangat dekat dengan Massudilalong pergi mengambil air nira yang berada di dekat kuburan Lebonna. Dodeng mendengar rintihan Lebonna meminta Dodeng untuk menyampaikan pesan kepada Massudilalong agar menepati janji yang telah mereka ikrarkan. Dodeng pun menyampaikan pesan Lebonna, dan Massudilalong pergi untuk membuktikannya. Setelah membuktikan sendiri, massudilalong 
merasa sangat terpukul lalu memutuskan untuk menepati janjinya. Massudilalong membuat upacara Ma'bua, dengan menyuruh setiap orang yang membawa babi harus membawa pula tombak yang ditancapkan ke tanah dengan mata tombak mengarah ke atas. Lalu, Massudilalong naik ke atas pendopo dan menjatuhkan dirinya tepat mengarah di mata tombak yang tertancap. Massudilalong pun meninggal. Namun, arwah Massudilalong terus datang ke rumahnya sebanyak tiga kali, hingga Dodeng menceritakan kepada keluarga mengenai kejadian yang sesungguhnya. Massudilalong pun dimakamkan bersama dengan Lebonna.

Tabel 1 Tokoh dalam Legenda Lebonna Massudilalong

\begin{tabular}{|c|c|c|c|}
\hline Pemeran & Tokoh & Karakter & Fisik \\
\hline \multirow[t]{2}{*}{$\begin{array}{l}\text { Pemeran } \\
\text { Utama }\end{array}$} & Lebonna & $\begin{array}{l}\text { Protagonis } \\
\text { : Baik hati, } \\
\text { setia }\end{array}$ & $\begin{array}{l}\text { Perempua } \\
\text { n cantik, } \\
\text { kulit } \\
\text { putih, } \\
\text { hidung } \\
\text { mancung, } \\
\text { rambut } \\
\text { panjang } \\
\text { dan } \\
\text { tinggi. }\end{array}$ \\
\hline & $\begin{array}{l}\text { Massudi } \\
\text { lal ong }\end{array}$ & $\begin{array}{l}\text { Protagonis } \\
\text { : Baik, } \\
\text { pintar, } \\
\text { pemberani } \\
\text {, setia, dan } \\
\text { pemaaf. }\end{array}$ & $\begin{array}{l}\text { Laki-laki } \\
\text { yang } \\
\text { gagah } \\
\text { berani, } \\
\text { tampan, } \\
\text { dan } \\
\text { tinggi. }\end{array}$ \\
\hline \multirow[t]{2}{*}{$\begin{array}{l}\text { Pemeran } \\
\text { Pembantu }\end{array}$} & $\begin{array}{l}\text { Paereng } \\
\text { an }\end{array}$ & Lucu, imut & $\begin{array}{l}\text { Masih } \\
\text { bayi }\end{array}$ \\
\hline & Dodeng & $\begin{array}{l}\text { Protagonis } \\
\text { : Baik hati, } \\
\text { jujur, }\end{array}$ & $\begin{array}{l}\text { Laki-laki } \\
\text { sederhana, } \\
\text { gagah dan } \\
\text { pemberani }\end{array}$ \\
\hline \multirow{3}{*}{$\begin{array}{l}\text { Pemeran } \\
\text { Pembantu } \\
\text { Pemeran } \\
\text { Pembantu }\end{array}$} & $\begin{array}{l}\text { Pengaw } \\
\text { al }\end{array}$ & $\begin{array}{l}\text { Bertanggu } \\
\text { ng jawab }\end{array}$ & $\begin{array}{l}\text { Laki-laki, } \\
\text { kurus dan } \\
\text { tinggi }\end{array}$ \\
\hline & $\begin{array}{l}\text { Anak } \\
\text { buah }\end{array}$ & $\begin{array}{l}\text { Antagonis: } \\
\text { Permboho } \\
\text { ng, licik } \\
\text { dan tidak } \\
\text { bertanggu } \\
\text { ng jawab }\end{array}$ & $\begin{array}{l}\text { Laki-laki, } \\
\text { tinggi }\end{array}$ \\
\hline & & $\begin{array}{l}\text { Baik, } \\
\text { pekerja } \\
\text { keras, dan }\end{array}$ & $\begin{array}{l}\text { Laki-laki, } \\
\text { gendut, }\end{array}$ \\
\hline
\end{tabular}

\begin{tabular}{|l|l|l|l|}
\hline & $\begin{array}{l}\text { Pembaw } \\
\text { a babi 1 }\end{array}$ & $\begin{array}{l}\text { bertanggu } \\
\text { ng jawab }\end{array}$ & $\begin{array}{l}\text { buncit, } \\
\text { pendek }\end{array}$ \\
\hline & $\begin{array}{l}\text { Pembaw } \\
\text { a babi 2 }\end{array}$ & $\begin{array}{l}\text { Baik, } \\
\text { pekerja } \\
\text { keras, dan } \\
\text { bertanggu } \\
\text { ng jawab }\end{array}$ & $\begin{array}{l}\text { Laki-laki, } \\
\text { gemuk }\end{array}$ \\
\cline { 2 - 4 } & $\begin{array}{l}\text { Gagah dan } \\
\text { pemberani }\end{array}$ & Laki-laki \\
\hline & $\begin{array}{l}\text { Kasukan } \\
\text { Keluarg } \\
\text { Massudi } \\
\text { lal ong }\end{array}$ & Baik & perempua n \\
\hline
\end{tabular}

Tabel 2 Storyline dan Storyboard Legenda Lebonna Massudilalong

\begin{tabular}{|c|c|c|}
\hline No. & Storyline & Storyboard \\
\hline 1. & $\begin{array}{l}\text { Lebonna } \\
\text { seorang gadis } \\
\text { yang cantik. }\end{array}$ & \\
\hline 2. & $\begin{array}{l}\text { Lebonna dan } \\
\text { Massudilalong } \\
\text { saling jatuh } \\
\text { hati. }\end{array}$ & \\
\hline 3. & $\begin{array}{l}\text { Lebonna dan } \\
\text { Massudilalong } \\
\text { berjanji sehidup } \\
\text { semati. }\end{array}$ & \\
\hline 4. & $\begin{array}{c}\text { Kemesraan } \\
\text { Lebonna dan } \\
\text { Massudilalong } \\
\text { membuat orang } \\
\text { iri hati. }\end{array}$ & \\
\hline 5. & $\begin{array}{l}\text { Massdudilalong } \\
\text { dan pasukan } \\
\text { pergi ke medan } \\
\text { perang. }\end{array}$ & \\
\hline 6. & $\begin{array}{l}\text { Lebonna } \\
\text { menenun ketika } \\
\text { menunggu } \\
\text { Massudilalong } \\
\text { pulang. }\end{array}$ & \\
\hline
\end{tabular}




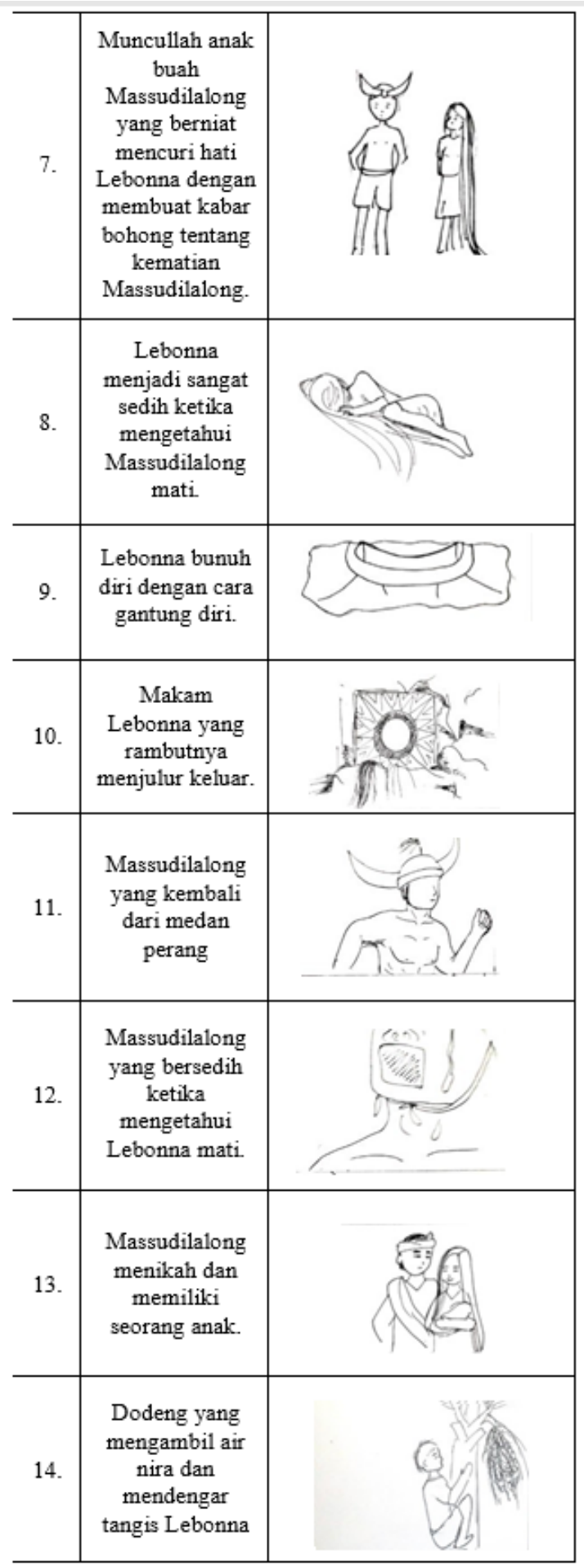

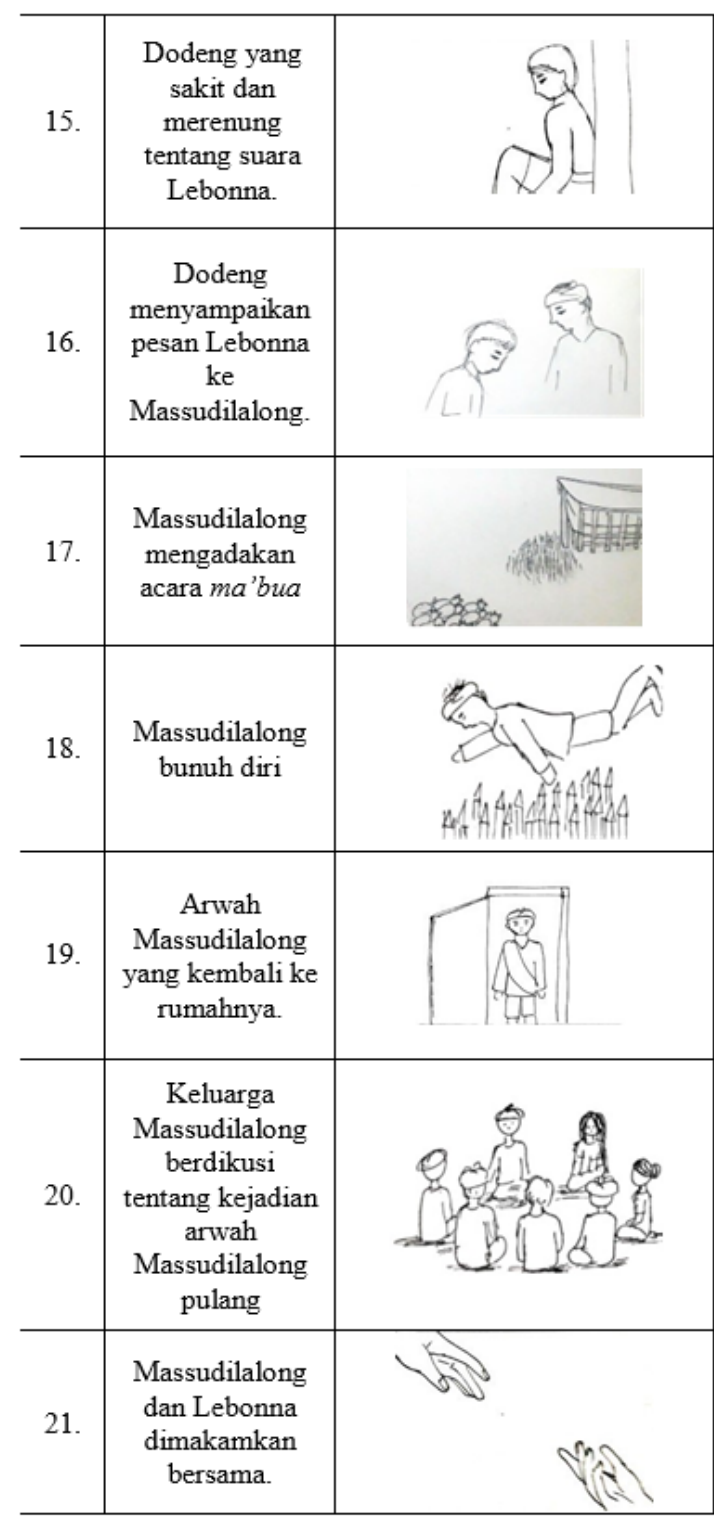

Target Audiens

Target audiens spesifik yaitu remaja laki-laki dan perempuan yang berusia 11 hingga 24 tahun yang berada di Indonesia khususnya daerah Tana Toraja. Remaja penikmat karya seni

visual seperti ilustrasi dan cerita rakyat baik yang berada di kota maupun desa.

\section{Visual Branding}

Ciri khas atau citra yang akan dibangun adalah cerita yang penuh emosi dengan genre romance, horror dan berakhir sedih dengan berlatarkan tradisional atau budaya Tana Toraja. 
Gaya Visual

Gaya visual yang akan digunakan adalah Semicartoon Style karena memiliki banyak peminat dikalangan remaja dan lebih cocok digunakan untuk cerita Lebonna Massudilalong.

Tipografi

Tipografi yang akan digunakan adalah kelompok jenis huruf serif karena sifatnya yang memberi kesan nyaman saat membaca. Huruf yang digunakan untuk judul cerita yaitu Romance Fatal Serif Std dan untuk isi cerita adalah Althea. Alasan pemilihan font tersebut disesuaikan dengan genre cerita yaitu romance, horror dan sad ending.

Romance Fatal Serif Std Romance Fatal Serif Std

\section{ABCDEFG HIJKLMNO PQRSTUVWXYZ Abcdefghijkl mnopqrstuvwxyz 0123456789}

Althea Althea Althea

\section{ABCDEFGHIJKL MNOPQRSTUVWXYZ Abcdefghijkl mnopqrstuvwxyz 0123456789}

Warna

Warna dominan yang akan digunakan adalah merah, kuning, hitam dan putih karena merupakan ciri khas dari daerah Toraja. Serta warna yang selaras dengan warna tersebut.

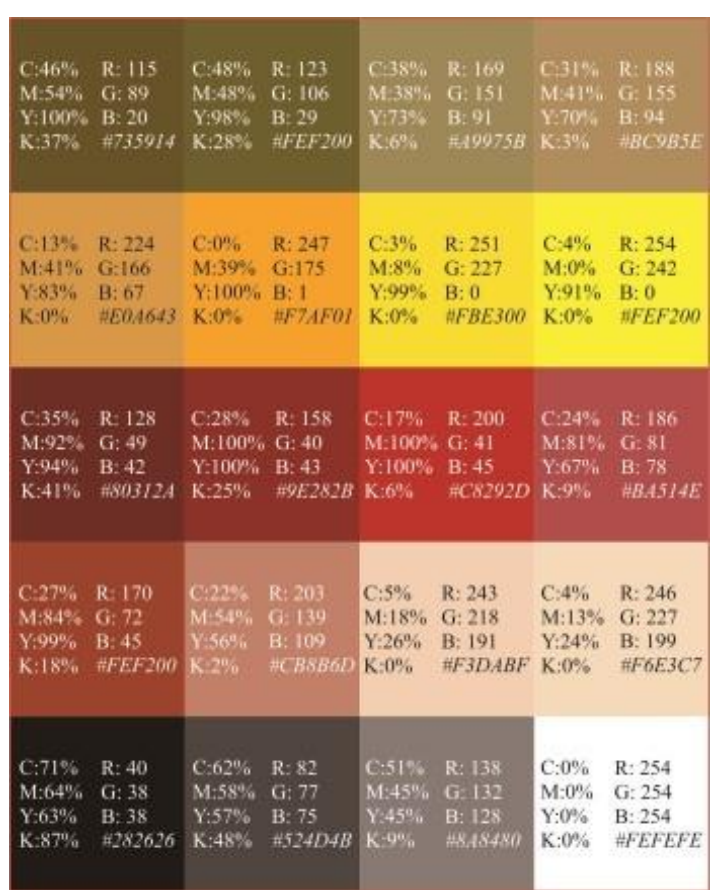

Gambar 1. Tampilan Warna yang akan Digunakan (Sumber: Olahan Penulis, 2019)

Karakter Lebonna

Sumber inspirasi berasal dari wanita Toraja dengan ciri-ciri:

- Wajah bulat

- Hidung mancung

- Kulit putih

- Tinggi

- Berambut sangat panjang

- Menggunakan pakaian pokko berwarna putih (baju lengan pendek dengan rok span). Tanpa menggunakan kandure.

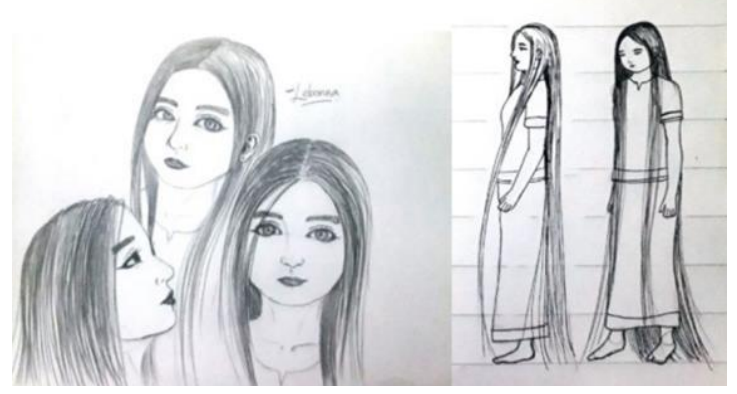

Gambar 2. Sketsa Karakter Lebonna (Sumber: Olahan Penulis, 2019) 
Karakter Massudilalong

Sumber inspirasi adalah pahlawan dari Toraja yaitu Pongtiku, dengan ciri-ciri:

- Berwajah bulat (rahang besar)

- Tinggi

- Gagah perkasa

- Menggunakan baju lengan panjang, celana pendek, sarung dan passapu ketika hari-hari tertentu.

- Mengenakan celana pendek, sarung, passapu dan tanpa baju atau telanjang dada ketika hari biasa atau sedang bertarung.

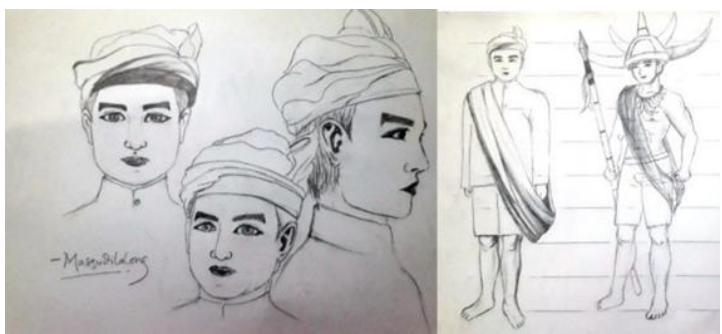

Gambar 3. Sketsa Karakter Massudilalong (Sumber: Olahan Penulis, 2019)

\section{Karakter Dodeng}

- Berwajah bulat

- Mengenakan celana pendek tanpa baju atau bertelanjang dada.

- Berambut pendek

- Ada keriput

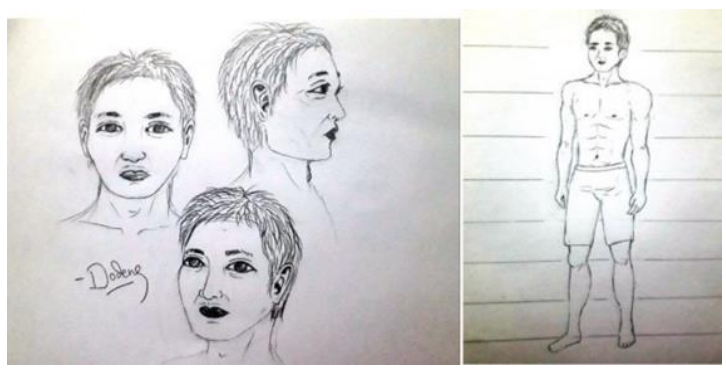

Gambar 4. Sketsa Karakter Dodeng (Sumber: Olahan Penulis, 2019)

\section{Media Utama}

Pada perancangan ini, buku ilustrasi dibuat berbentuk persegi dengan ukuran $20 \mathrm{~cm}$ x $20 \mathrm{~cm}$, berjumlah 46 halaman yang memuat gambar dan teks. Ilustrasi yang digunakan merupakan ilustrasi bergaya semi kartun dengan teknik digital art.
Sampul

Halaman sampul pada bagian depan terdapat ilustrasi Lebonna dan pada bagian belakang ilustrasi Massudilalong. Massudilalong dan Lebonna diilustrasikan terbaring sambil menutup mata, lalu rambut Lebonna seakan menutup mata dan mengikat kepala serta leher Massudilalong, artinya mereka saling terikat. Lebonna yang mati bunuh diri dengan cara gantung diri menagih janji sehidup semati kepada Massudilalong.

Peletakan ilustrasi Lebonna di bagian depan sampul artinya Lebonna mati terlebih dahulu dan Massudilalong dibelakang sampul artinya ia mati setelah Lebonna demi menepati janjinya. Pada depan sampul terdapat teks judul cerita dengan menggunakan font Romance Fatal Serif Std yang dimodifikasi dan dilayout sedemikian rupa agar terlihat menarik.
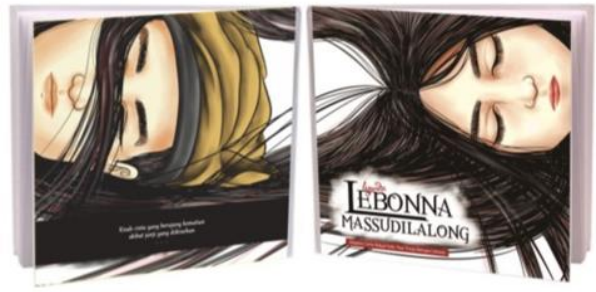

Gambar 5. Final Desain Sampul Depan dan Belakang (Sumber: Olahan Penulis, 2019)

Ilustrasi Isi Buku

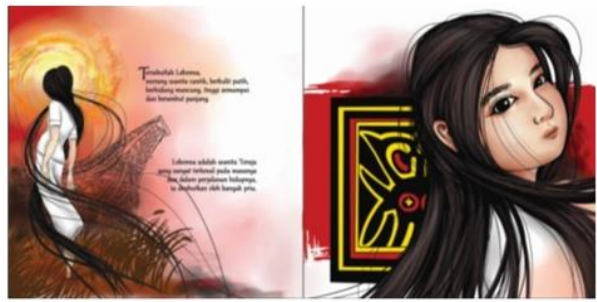

Gambar 6. Final Desain Halaman 1 dan 2 (Sumber: Olahan Penulis, 2019)

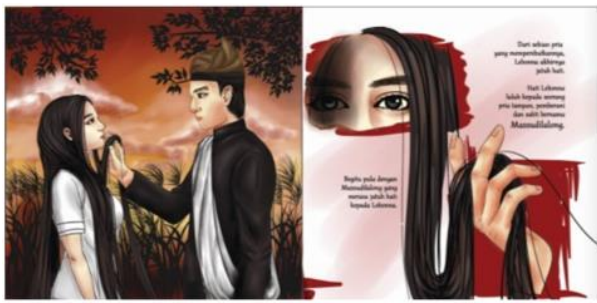

Gambar 7. Final Desain Halaman 3 dan 4 (Sumber: Olahan Penulis, 2019) 


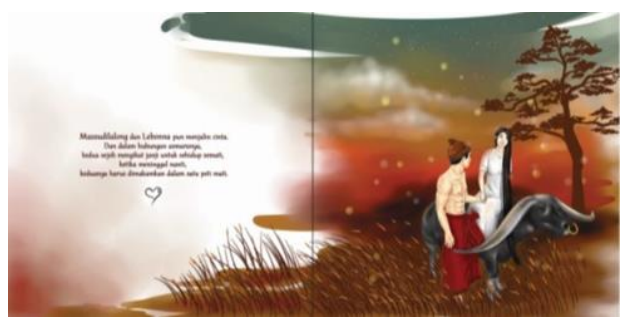

Gambar 8. Final Desain Halaman 5 dan 6 (Sumber: Olahan Penulis, 2019)

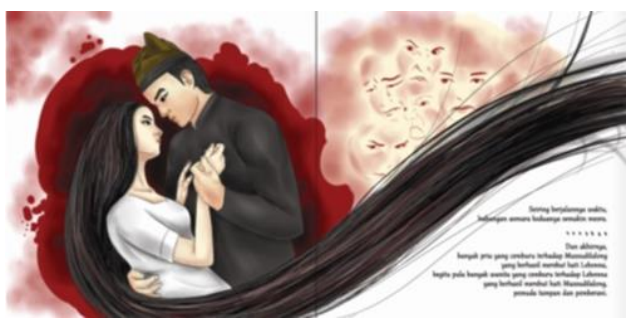

Gambar 9. Final Desain Halaman 7 dan 8 (Sumber: Olahan Penulis, 2019)

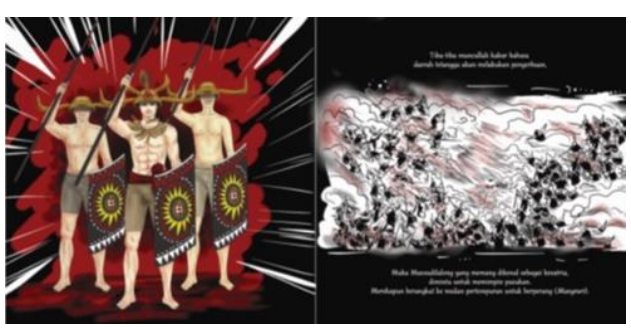

Gambar 10. Final Desain Halaman 9 dan 10 (Sumber: Olahan Penulis, 2019)

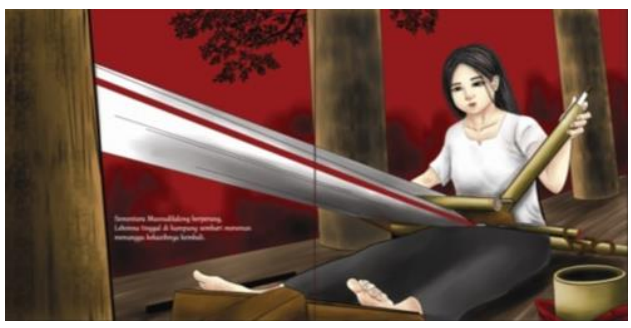

Gambar 11. Final Desain Halaman 11 dan 12 (Sumber: Olahan Penulis, 2019)

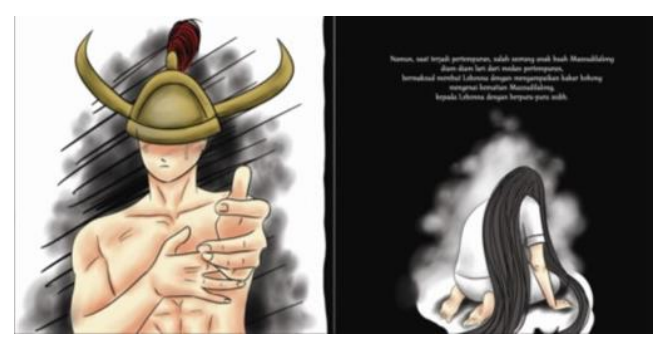

Gambar 12. Final Desain Halaman 13 dan 14 (Sumber: Olahan Penulis, 2019)

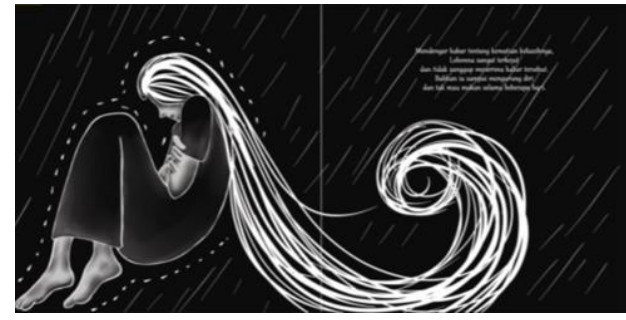

Gambar 13. Final Desain Halaman 15 dan 16 (Sumber: Olahan Penulis, 2019)

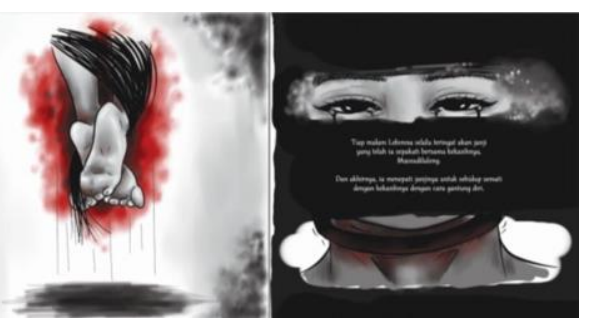

Gambar 14. Final Desain Halaman 17 dan 18 (Sumber: Olahan Penulis, 2019)

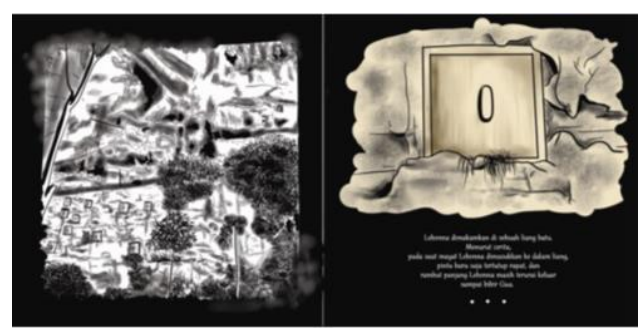

Gambar 15. Final Desain Halaman 19 dan 20 (Sumber: Olahan Penulis, 2019)

\section{Media Pendukung}

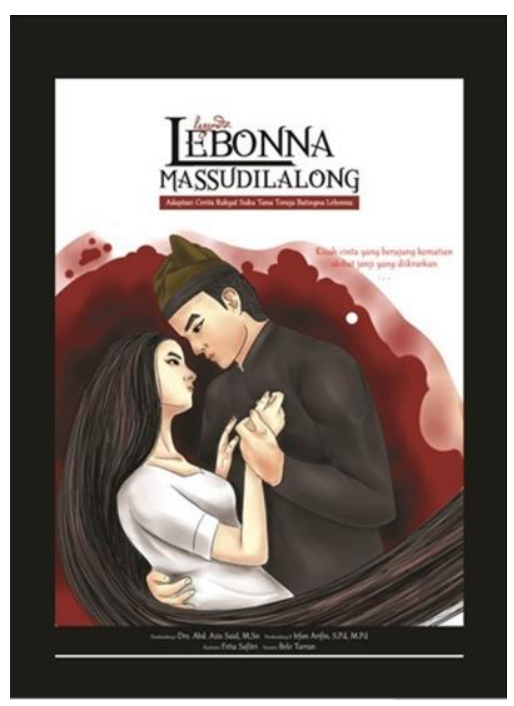

Gambar 16. Final Desain Poster (Sumber: Olahan Penulis, 2019) 

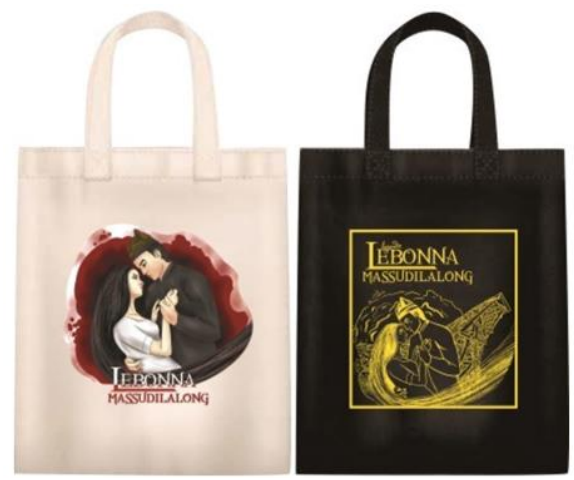

Gambar 17. Final Desain Totebag (Sumber: Olahan Penulis, 2019)
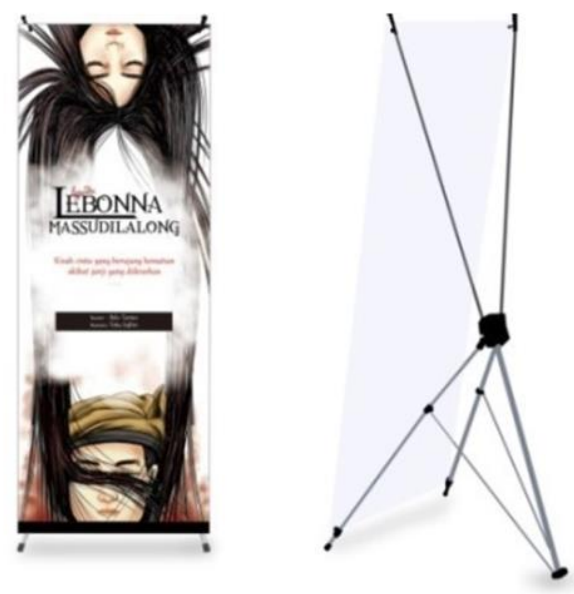

Gambar 18. Final Desain X banner (Sumber: Olahan Penulis, 2019)
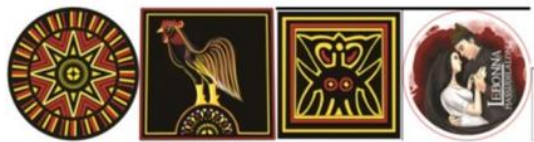

\section{EEBONNA}

Gambar 19. Final Desain Stickers (Sumber: Olahan Penulis, 2019)

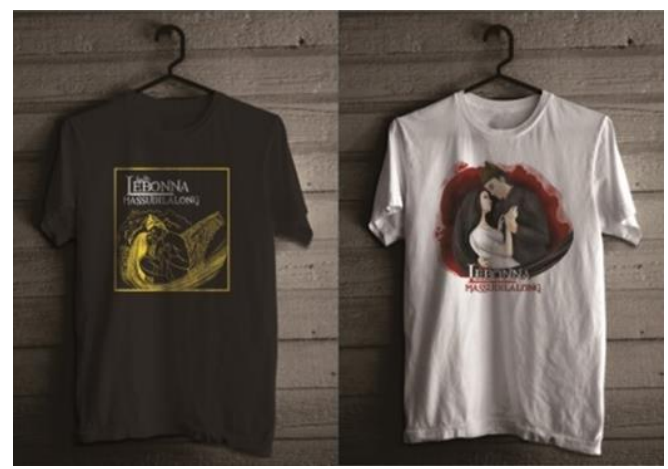

Gambar 20. Final Desain T-Shirt (Sumber: Olahan Penulis, 2019)

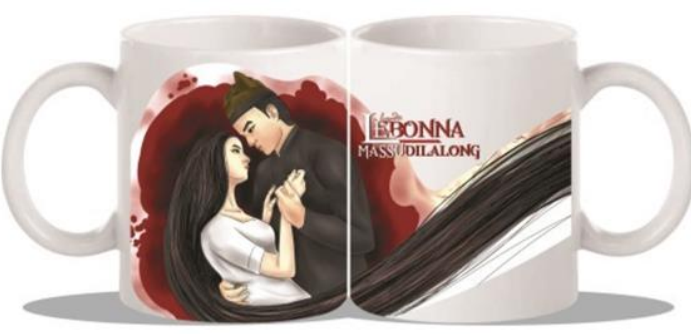

Gambar 21. Final Desain Mug (Sumber: Olahan Penulis, 2019)

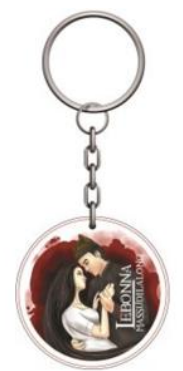

Gambar 22. Final Desain Gantungan Kunci

(Sumber: Olahan Penulis, 2019)

\section{SIMPULAN DAN SARAN}

Karya yang dibuat adalah ilustrasi cerita rakyat Lebonna Massudilalong dengan buku fisik sebagai media utamanya. Pada perancangan ini, buku ilustrasi dibuat berbentuk persegi dengan ukuran $20 \mathrm{~cm}$ x 20 $\mathrm{cm}$, berjumlah 46 halaman yang memuat gambar dan teks. Ilustrasi yang digunakan merupakan ilustrasi bergaya semi kartun dengan teknik digital art. Konsep desain yang digunakan adalah romance classic dengan pewarnaan khas yang berasal dari daerah Toraja yaitu merah, kuning, putih dan hitam, dengan menggunakan font Romance Fatal Serif Std sebagai judul cerita dan font Althea sebagai isi cerita, dengan target audiens ramaja.

Sedangkan untuk media pendukung yang berfungsi sebagai media penyalur informasi yaitu berupa poster, x-banner, totebag, mug, sticker, t- shirt, dan gantungan kunci. Semua media pendukung dibuat atau didesain dengan memasukkan bagian adegan dan judul dari cerita rakyat Lebonna Massudilalong agar mudah untuk dikenali.

Perancangan buku ilustrasi cerita rakyat atau legenda Lebonna Massudilalong masih memiliki kekurangan dan perlu untuk 
dikembangkan maupun perbaikan. Hal itu terkait dengan tampilan visual yang disajikan dari buku ilustrasi sendiri maupun media pendukung yang berfungsi sebagai media promosi yang bertujuan untuk menyampaikan pesan kepada pembaca. Tampilan visual karakter maupun ilustrasi dapat dikembangkan maupun diperbaiki sesuai dengan target audiens begitu pula dengan media promosinya. Serta perlu adanya usaha untuk menerbitkan buku ilustrasi Legenda Lebonna Massudilalong agar perancangan tidak sia-sia.

\section{REFERENSI}

Anne Veronica h, d. B. (2015). Perancangan Media Digital Interaktif Sebagai Pengenalan Cerita Rakyat Indonesia Untuk Anak Usia 10-12 Tahun. Kelompok penelitian, 25.

Dina Gasong, M. D. (2018). Kearifan Lokal Dalam Cerita Rakyat Toraja. Gasong, Simega \& Rumpa, 941-941.

Fitri Sundari, E. S. (2017). Penerapan Program Fos (Folktale Speaking) Sebagai. Jurnal Pendidikan Ilmu-Ilmu Sosial, 103.

Hillary, J. (2018). Tipologi Cerita Lebonna Massudilalong Sebuah Kajian Struktural. Skripsi, 1.

Putro, K. Z. (2017). Memahami Ciri Dan Tugas Perkembangan Masa Remaja. Jurnal Aplikasi Ilmu-Ilmu Agama, 25.

Said, A. A. (2004). Simbolisme Unsur Visual Rumah

Tradisional Toraja. Yogyakarta: Ombak, 21.

Said, A. A. (2006). Dasar Desain Dwimatra. Makassar: UNM Makassar, 5.

Tarran, B. (2019, Mei 1). Perbedaan Versi Cerita Rakyat Lebonna Massudilalong. (F. Safitri, Interviewer) 